\title{
Global Interest for Health Professions Education: A Geographic and Temporal Analyses Through Web Search Differences from 2010-2019
}

Junhel Dalanon

Southwestern University PHINMA, School of Dentistry, jcdalanon.swu@phinmaed.com

Yoshizo Matsuka

Tokushima University Graduate School of Biomedical Sciences, matsuka@tokushima-u.ac.jp

Follow this and additional works at: https://nsuworks.nova.edu/ijahsp

Part of the Dental Public Health and Education Commons, Educational Leadership Commons, Health Information Technology Commons, Interprofessional Education Commons, Neuroscience and Neurobiology Commons, and the Prosthodontics and Prosthodontology Commons

\section{Recommended Citation}

Dalanon J, Matsuka Y. Global Interest for Health Professions Education: A Geographic and Temporal Analyses Through Web Search Differences from 2010-2019. The Internet Journal of Allied Health Sciences and Practice. 2020 Jan 01;18(3), Article 5.

This Manuscript is brought to you for free and open access by the College of Health Care Sciences at NSUWorks. It has been accepted for inclusion in Internet Journal of Allied Health Sciences and Practice by an authorized editor of NSUWorks. For more information, please contact nsuworks@nova.edu. 


\title{
Global Interest for Health Professions Education: A Geographic and Temporal Analyses Through Web Search Differences from 2010-2019
}

\begin{abstract}
Purpose: The purpose of this study was to analyze the spatio-temporal differences in web search trends for dental degrees (DD), medical degrees (MD), and nursing degrees (ND) across 197 countries from 2010 to 2019. Method: A search string was used to initiate a search query using Google Trends. The parameters used were DD, MD, and ND as search terms; worldwide as Location; 2010 to 2019 as time range; health education \& medical training as category; and web search as database. Data were downloaded and analyzed. Results: Via one-way ANOVA and post hoc Dunnett test, the searches for DD were found to be significantly lower in 2011 (3.2 $\pm 0.3, p=.044), 2012(2.6 \pm 0.2, p<.001), 2013(2.8 \pm 0.3, p=.006), 2014$ $(3.0 \pm 0.3, p=.017)$, and $2015(2.9 \pm 0.3, p=.010)$ compared to the year $2010(4.5 \pm 0.6)$; the searches for MD was significantly higher in 2019 (84.5 $\pm 2.5, p=.002)$ compared to the year 2010 (73.0 \pm 1.7$)$; and the searches for ND were statistically significantly higher in $2015(28.9 \pm 1.1, p=.024)$ and $2019(31.7 \pm 1.1, p$ $=.001)$ compared to the year $2010(24.5 .0 \pm 1.2)$. The search trend for MD increased in 31 countries and decreased in 14 countries while searches for ND increased in 40 countries and decreased in 5 countries as determined by a two-way ANOVA with Holm-Sidak's multiple comparison test. The 12-month forecast for the search interests of these health professions predicted a rise in the third quarter and an abrupt decline at the end of the year. Conclusions: Geographic and time factors affect the search interests for health professions. In a span of a decade, the disparity of interests shown by the low interests for DD and ND compared to MD in some countries underscores the need to promote these professions to fill the future health care workforce.
\end{abstract}

\section{Author Bio(s)}

Junhel Dalanon, DMD, MAT, EdD, is an Associate Professor in the School of Dentistry at Southwestern University PHINMA. He is also a member of the Department of Stomatognathic Function and Occlusal Reconstruction at Tokushima University Graduate School of Biomedical Sciences.

Yoshizo Matsuka, DDS, PhD, is a Professor in the Department of Stomatognathic Function and Occlusal Reconstruction at Tokushima University Graduate School of Biomedical Sciences. 


\title{
TIAHSP \\ The Internet Journal of Allied Health Sciences and Practice \\ Dedicated to allied health professional practice and education \\ Vol. 18 No. 3 ISSN 1540-580X
}

\section{Global Interest for Health Professions Education: A Geographic and Temporal Analyses Through Web Search Differences from 2010-2019}

\author{
Junhel Dalanon ${ }^{1}$ \\ Yoshizo Matsuka² \\ 1. Southwestern University PHINMA \\ 2. Tokushima University
}

Philippines and Japan

\begin{abstract}
ABTRACT
Purpose: The purpose of this study was to analyze the spatio-temporal differences in web search trends for dental degrees (DD), medical degrees (MD), and nursing degrees (ND) across 197 countries from 2010 to 2019. Method: A search string was used to initiate a search query using Google Trends. The parameters used were DD, MD, and ND as search terms; worldwide as Location; 2010 to 2019 as time range; health education \& medical training as category; and web search as database. Data were downloaded and analyzed. Results: Via one-way ANOVA and post hoc Dunnett test, the searches for DD were found to be significantly lower in 2011 (3.2 $\pm 0.3, p=.044), 2012(2.6 \pm 0.2, p<.001), 2013(2.8 \pm 0.3, p=.006), 2014(3.0 \pm 0.3, p=.017)$, and $2015(2.9 \pm 0.3, p=$ $.010)$ compared to the year 2010 ( $4.5 \pm 0.6)$; the searches for MD was significantly higher in $2019(84.5 \pm 2.5, p=.002)$ compared to the year $2010(73.0 \pm 1.7)$; and the searches for ND were statistically significantly higher in $2015(28.9 \pm 1.1, p=.024)$ and 2019 $(31.7 \pm 1.1, p=.001)$ compared to the year 2010 (24.5.0 \pm 1.2$)$. The search trend for MD increased in 31 countries and decreased in 14 countries while searches for ND increased in 40 countries and decreased in 5 countries as determined by a two-way ANOVA with Holm-Sidak's multiple comparison test. The 12-month forecast for the search interests of these health professions predicted a rise in the third quarter and an abrupt decline at the end of the year. Conclusions: Geographic and time factors affect the search interests for health professions. In a span of a decade, the disparity of interests shown by the low interests for DD and ND compared to MD in some countries underscores the need to promote these professions to fill the future health care workforce.
\end{abstract}

Keywords: career choice, spatio-temporal analysis, data mining, information seeking behavior 


\section{INTRODUCTION}

Under the 2030 Agenda for Sustainable Development, ensuring healthy lives and the promotion of well-being across all ages is the third sustainable development goal. ${ }^{1}$ This sustainable development goal is the very essence of universal health care (UHC) coverage. A substantial number of individuals effectively trained in health professions education are required in attaining UHC. Regulating health worker jobs and comprehensively subsidizing the training of health care professionals is crucial. This concept is acknowledged by nearly all countries. ${ }^{2}$

The decreasing mortality and consequential aging of people all over the world are associated with the intensification of chronic diseases and disability with outright increases in years lived with disability, according to the Global Burden of Disease Study. For 139 of 188 countries between 1990 and 2013, years lived with disability increased in both high-income countries along with the low- and middle-income countries. Multimorbidity is the term used for the phenomenon suffered by increasing numbers of people suffering from multiple conditions. ${ }^{3}$

Treatment of simple conditions begins at the community level and is easily controlled. These multimorbid conditions complicate the health care system as they are complex conditions that require professionals with advanced knowledge and training in treating these conditions. These conditions use a more expensive treatment option. Health workers are scarce in many countries. By 2025, a 27\% shortage of primary care physicians is foreseen in the United States. ${ }^{4}$ This problem is comparable with Australia, New Zealand, South Africa, Brazil, China, India, and Russia.,6, In 1978, almost all global health advocates and governments who attended the International Conference on Primary Health held in Alma, Ata, realized the prevailing blatant inequality in health status levels between developing and developed countries. ${ }^{7}$

There were a weak knowledge base, negative work environment, maldistribution, worker shortage, skill mix imbalance, and a projected world shortage of more than four million health workers as problems. ${ }^{8}$ Regional and country-specific differences may arise, but typically, a country just allocates $42 \%$ of its total general government health expenditure for payment to its health workforce. ${ }^{9}$ There is also a longstanding dilemma of uneven distribution of health workers across the globe. Countries with the greatest burden of disease have the lowest number of health workers, whereas, those with the lowest relative need have the highest number of health workers. There is an uneven distribution of health workers. ${ }^{10}$ Public health is impaired when health workers are scarce as insinuated by the association between the coverage of health services and accessibility of health care workers. ${ }^{11-13}$ According to the 2006 World Health Organization Report, 36 of 46 countries in Africa, 5 of 35 in the Americas, 6 of 11 in South-East Asia, 0 of 52 in Europe, 7 of 21 in Eastern Mediterranean, and 3 of 27 in the Western Pacific are having a critical shortage in doctors, nurses, and midwives.

There is a dearth of information regarding global data about the world's interest in health professions education. Using spatio- temporal analyses, these investigators evaluated the time-dependent and geographic differences in search interests for the pre-selected health professions degree per country from 2010 to 2019. These investigators aimed to unveil differences for web searches among and within the health professions degree from 2011 to 2019 when compared with 2010 and to distinguish which countries have high or low search interests when search volumes from 2011 to 2019 were compared with those from 2010.

\section{METHODS}

\section{Ethical Considerations}

The Institutional Review Board of Southwestern University PHINMA approved this study to be exempt and confirmed that no human or animal experiment was performed in this research.

\section{Research Design}

These investigators utilized data mining in gathering the required documents and used spatio-temporal analyses in assessing the differences in the Internet search trends for health professions education.

\section{Search Query}

Other researchers have data-mined Google Trends (GT), Facebook, and Twitter to locate the incidence of diseases and forecast epidemiologic phenomenon. ${ }^{14-22}$ In this study, a search string was used to make a search query through GT using the parameters dental degree, medical degree, and nursing degree as search terms; worldwide as location; January 1, 2010, to December 31, 2019, as time range; health education and medical training as category; and web search as database. A comma-separated value (CSV) file containing interests-over-time information of the parameters was downloaded. This specific data set was used for the temporal analyses. Subsequently, 10 separate search queries were made using the same parameters but with a varying time range. The 10 ranges of time included the individual years from 2010 to 2019 when the start of every time span is January 1 and the end is December 31. The data sets from these searches contained breakdown comparisons per country and were used for geographic analyses. The numbers or values found in the CSV files represented the Internet search interests in relation to the highest peak for the given country 
and time. This search is the relative search value (RSV), which is expressed in peak popularity rate in percentage. A score of $0 \%$ means that the data for this period was not enough, 50\% means the search terms are half as popular, and $100 \%$ is the maximum score attainable.

\section{Statistical Analyses}

Column data tables were made by manually importing the data from the CSV files and entering replicate values that were stacked into columns corresponding individual years from 2010 to 2019. Another data table was made to import all data from the first search query and entered as 12 replicate values in side-by-side subcolumns. The columns were categorized per search term, and rows were labeled per year. The first 3 data sets were used to assess the differences in search trends for DD, MD, and ND through an ordinary one-way analysis of variance (ANOVA) with Dunnett's multiple comparison test with a single pooled variance. The mean of each year from 2011 to 2019 was compared to the year 2010. The last data set was used to compare the average RSV between DD, MD, and ND from 2010 to 2019 using a one-way ANOVA with Tukey's post hoc test.

To test for geographic disparities in search trends, column data tables were added to accommodate the transfer of data from the CSV files. These correspond to the RSV for DD per country, MD per country, and ND per country. These data sets were used to analyze individually the differences of searches for $\mathrm{DD}, \mathrm{MD}$, and ND per country through an ordinary two-way ANOVA with Holm-Sidak's multiple comparison test with individual variances computed for each comparison. The means of the RSV from 2011 to 2019 per country were compared with the year 2010. Descriptive and inferential statistics were done using GraphPad Prism version 8.0.1 (GraphPad Software, La Jolla, California, USA).

The time series modeler was used to make forecasting models based on monthly RSV data that spanned from 2010 to 2019 per search term. The expert modeler method was performed and fitted the simple seasonal model based on the residual autocorrelational function and the partial residual autocorrelation function. The 12-month forecast displayed the forecast period from January 2020 to December 2020. Time series modeling and forecasting were done using IBM SPSS 26 (SPSS Inc., Chicago, Illinois, USA).

\section{RESULTS}

Out of 197 countries in the database of GT, only $45(22.9 \%)$ countries elicited responses or interest towards the health professions degrees.

\section{Temporal Variations in Search Trends for Health Professions Education}

There was a statistically significant difference between the RSV for DD per year as determined by one-way ANOVA, $F(9,110)=$ 2.474, $p=.013$. A Dunnett post hoc test showed that the searches for DD were statistically significantly lower in $2011(3.2 \pm 0.3, p=$ $.044), 2012$ (2.6 $\pm 0.2, p<.001), 2013$ (2.8 $\pm 0.3, p=.006), 2014$ (3.0 $\pm 0.3, p=.017)$, and $2015(2.9 \pm 0.3, p=.010)$ compared to the year $2010(4.5 \pm 0.6)$. There were no statistically significant differences in the years $2016(p=.153), 2017(p=.302), 2018(p=$ .218 ), and $2019(p=.104)$ when compared to the year 2010 (Figure 1A).

As determined by one-way ANOVA, $F(9,110)=8.5, p<.001$, a statistically significant difference between the RSV for MD per year was found. A Dunnett post hoc test showed that the searches for MD was statistically significantly higher in $2019(84.5 \pm 2.5, p=$ $.002)$ compared to the year $2010(73.0 \pm 1.7)$. There were no statistically significant differences in the years $2011(p=.847), 2012(p$ $=.266), 2013(p=.293), 2014(p=.355), 2015(p=.917), 2016(p=.740), 2017(p=.193)$, and 2018

$(p=.089)$ when compared to the year 2010 (Figure 1B).

Using one-way ANOVA, $F(9,110)=3.489, p<.001$, a statistically significant difference between the RSV for ND per year was found. A Dunnett post hoc test showed that the searches for ND were statistically significantly higher in $2015(28.9 \pm 1.1, p=.024)$ and 2019 $(31.7 \pm 1.1, p=.001)$ compared to the year $2010(24.5 .0 \pm 1.2)$. There were no statistically significant differences in the years 2011 ( $p=.938), 2012(p>.999), 2013(p=.100), 2014(p=.100), 2016(p=.338), 2017(p=.658)$, and $2018(p=.166)$ when compared to the year 2010 (Figure 1C).

There was a statistically significant difference between the RSV for DD, MD, and ND as determined by one-way ANOVA, $F(2,27)=$ 846.4, $p<.001$. A Tukey post hoc test showed that the searches for $\operatorname{DD}(3.3 \pm 0.2, p<.001)$ were statistically significantly lower compared to MD $(74.2 \pm 2.0)$. The search volume for $\mathrm{DD}(3.3 \pm 0.2, p<.001)$ was also lower compared to ND $(27.7 \pm 0.8)$ while MD $(74.2 \pm 2.0, p<.001)$ was significantly higher than ND $(27.7 \pm 0.8$, see Figure $1 \mathrm{D})$. 

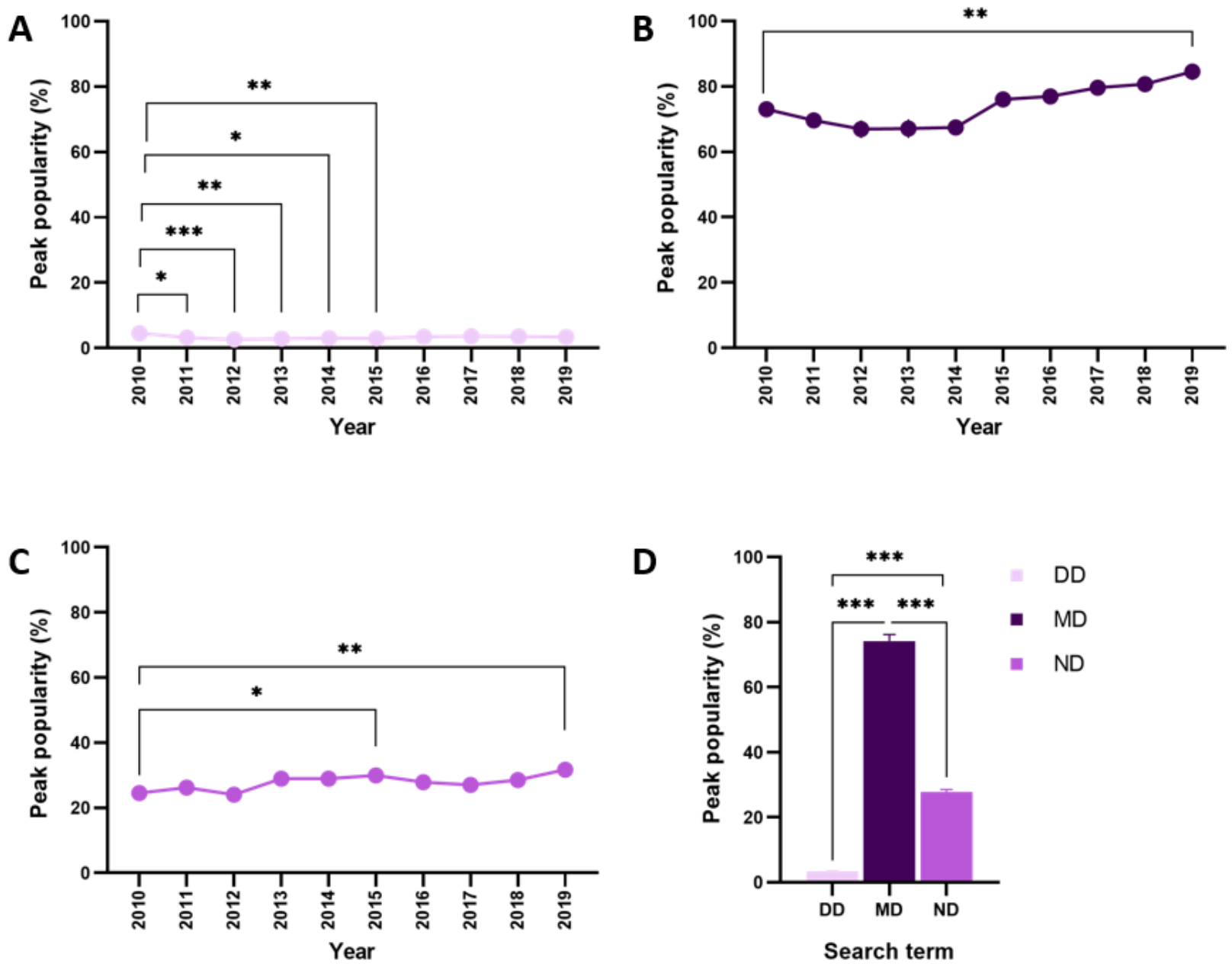

Figure 1: Considerable differences in peak popularity percentage for $(A) D D,(B) M D,(C) N D$, and $(D)$ among search terms. $\mathrm{DD}=$ dental degree, $\mathrm{MD}=$ medical degree, $N D=$ nursing degree. Note: $p<0.05^{*}, p<0.01^{* *}, p<0.001^{* * *}$

\section{Geographic Disparities in Searches for Health Professions Education}

An ordinary two-way ANOVA was conducted that compared the differences in the RSV for DD per country across the years from 2010 to 2019. There was no significant difference in the RSV for DD per country across the years from 2011 to 2019 when compared to the year 2010, $F(9,396)=1.372, p=.199$ (Figure 2A).

To evaluate the differences in the RSV for MD per country across the years from 2010 to 2019, a two-way ANOVA was conducted. There was a statistically significant difference in the RSV for MD per country, $F(9,396)=3.814, p<.001$. Holm-Sidak's multiple comparison test showed that the search trends for MD in 2019 when compared to 2010 significantly, increased for Canada, Colombia, France, Ghana, India, Indonesia, Iran, Ireland, Kenya, Malaysia, Nepal, Netherlands, New Zealand, Pakistan, Philippines, Qatar, Russia, Saudi Arabia, Singapore, South Africa, South Korea, Spain, Sri Lanka, St. Helena, Sweden, Taiwan, Thailand, Ukraine, Vietnam, Zambia, and Zimbabwe while it decreased for Australia, Bangladesh, Brazil, Egypt, Germany, Hong Kong, Italy, Japan, Mexico, Nigeria, Turkey, United Arab Emirates (UAE), United Kingdom (UK), and United States of America (USA, see Figure 2B).

The differences in the RSV for ND per country across the years from 2010 to 2019 were compared by performing a two-way ANOVA. There was a statistically significant difference in the RSV for ND per country, $F(9,396)=4.534, p<.001$. Holm-Sidak's multiple comparison test showed that the search trends for ND in 2019 when compared to 2010 significantly increased for Australia, Bangladesh, Brazil, Canada, Colombia, Egypt, France, Germany, Ghana, India, Indonesia, Iran, Italy, Kenya, Malaysia, Nepal, Netherlands, New Zealand, Nigeria, Pakistan, Philippines, Russia, Saudi Arabia, Singapore, South Africa, South Korea, Spain, Sri Lanka, St. Helena, Sweden, Taiwan, Thailand, Ukraine, UAE, UK, USA, Vietnam, Zambia, and Zimbabwe, and it decreased for Hong Kong, Japan, Mexico, Qatar, and Turkey (Figure 2C). 


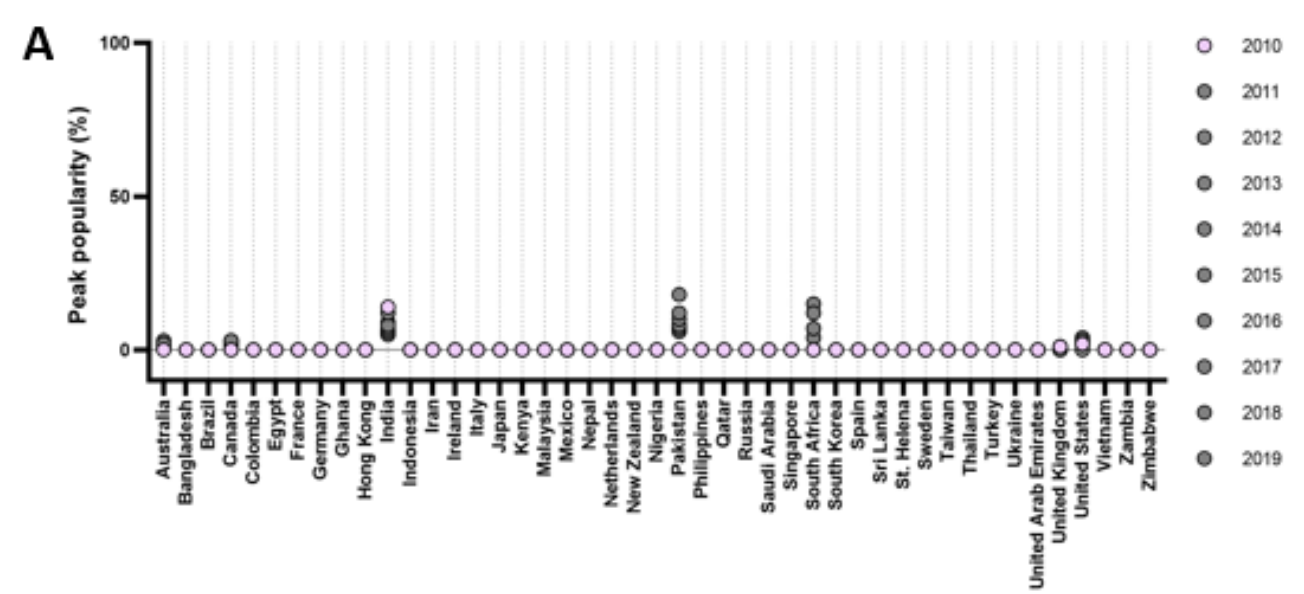

Country

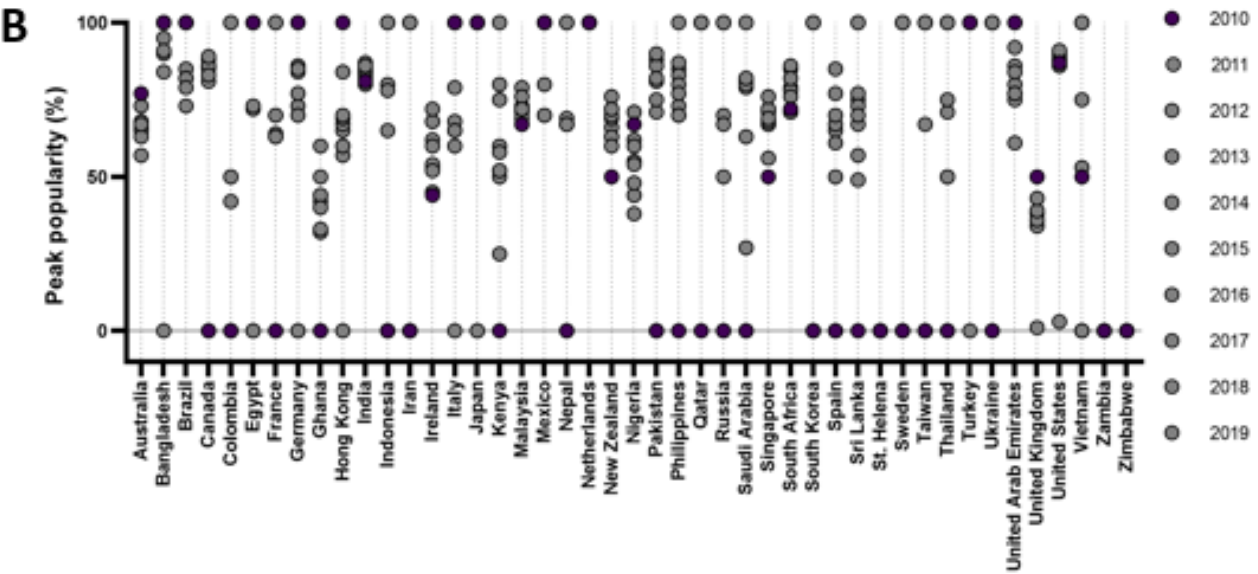

Country

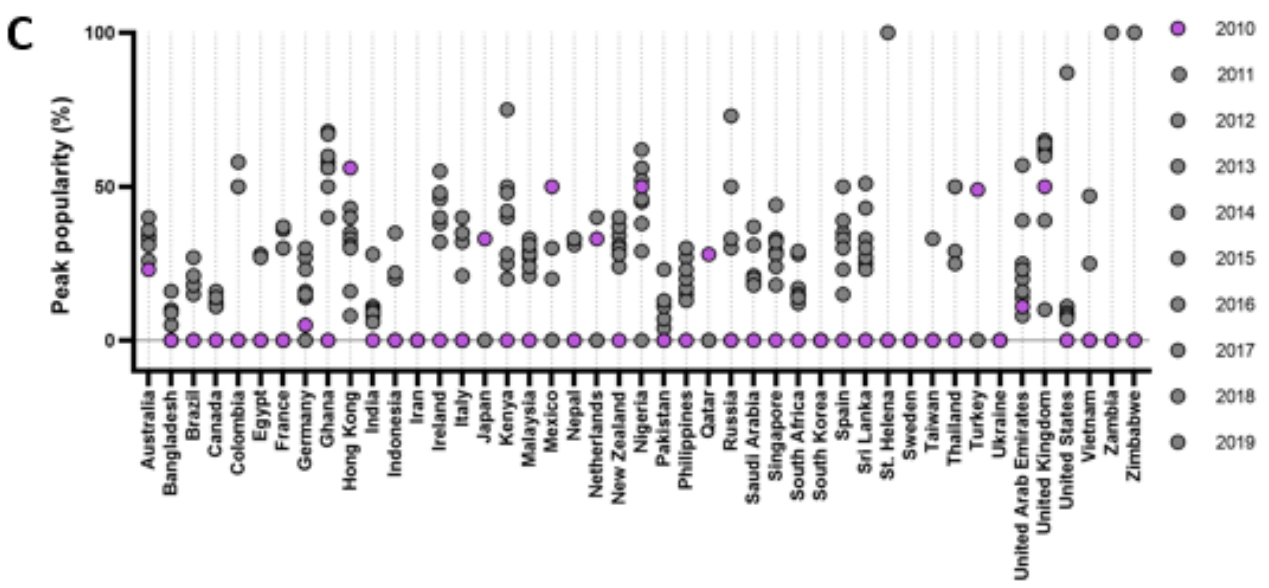

Country

Figure 2. Considerable differences in peak popularity percentage for (A) DD, (B) MD, and (C) ND among search terms per country. $\mathrm{DD}=$ dental degree, $\mathrm{MD}=$ medical degree, $\mathrm{ND}=$ nursing degree 


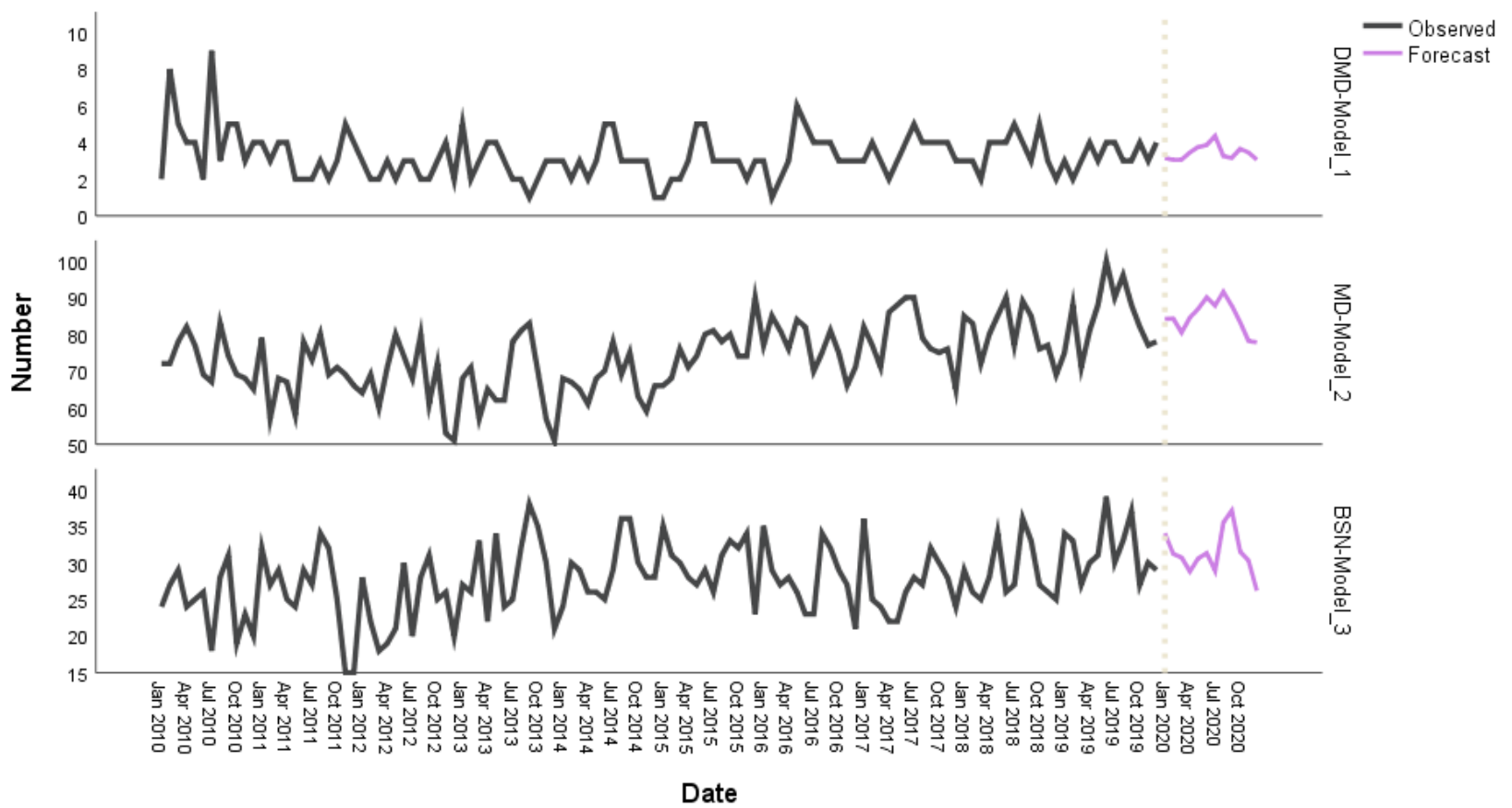

Figure 3. Forecast graph containing observed and forecasted trendlines of $D D, M D$, and ND searches using Simple Seasonal Model. $\mathrm{DD}=$ dental degree, $\mathrm{MD}=$ medical degree, $\mathrm{ND}=$ =nursing degree

\section{Forecast in Searches for Health Professions Education}

Using expert modeler, the forecast line of the RSV for DD will stabilize sub- $4 \%$ at the start of the year until the first part of the second quarter. It will have its peak just below $5 \%$ and will begin to regress in October. The trend line for MD will start rising in April and will continue to have its first high at $90 \%$ in July. Its highest peak just above $90 \%$ will be in the third quarter but will drop starting in October. Starting at $35 \%$, the RSV for ND will decline in the first quarter and will rise just above $30 \%$ in the second quarter. It will have its highest peak at $35 \%$ to $40 \%$ during the third quarter and will abruptly retrogress beginning October.

\section{DISCUSSION}

By the findings in this study, only 45 of $197(22.9 \%)$ countries were interested in health professions education. This finding is very alarming as the attainment of UHC is one of the core goals under the 2030 Agenda for Sustainable Development to ensure healthy lives and wider coverage of health across all ages. ${ }^{1}$ The remaining governments of the world that have not prioritized health care and health worker jobs should make a critical stand to acknowledge the importance of health to sustainable development. ${ }^{2}$

The popularity of DD decreased from 2011 to 2015 and subsequently recovered until currently. Shortage in dentists usually happens in rural and remote areas. A high density of dentists usually chose an urban practice for the obvious return of investments and the pride that goes with it. This shortage causes a shortage of dentists who are willing to serve the underserved in the rural and remote areas. ${ }^{23,24}$ This occurrence is not only strictly limited to developing countries, as it can also happen in some regions of developed countries. ${ }^{5}$

A rising trend was seen in the world's interest towards MD, which was significantly higher in 2019 than in 2010. The searches for MD were also seen to be higher than the other two health professions. Being a physician is appealing to prospective students, owing to its reputation and the perception of earning more than others. According to Gazibara, Kurtagic, Maric et al, in Serbia, among first-year and sixth-year medical students, the main reasons why they chose to study medicine were to help people, earn more, and social status. ${ }^{25}$ The trend line for ND was between MD and DD. An elevating trend was also seen with significant rises in 2015 and 2019. The world may have had recovered already from the great recession with global effects from 2008 to 2012.26 In the Western Pacific Region, the ratio of nurses to physicians is 1.5:1 compared to the African Region with an 8:1 ratio. In countries like Canada and the USA, there are four nurses to every doctor.

According to differences per country, MD suggestively decreased in interest with countries like Australia, Bangladesh, Brazil, Egypt, Germany, Hong Kong, Italy, Japan, Mexico, Nigeria, Turkey, UAE, UK, and the USA. These low scores could mean that there is 
already an oversaturation of physicians in developed countries. In the case of low- and middle-income countries, the creation and training of cadres may have already offset the need for physicians in these countries.

As the world is aging and needs to employ more nurses, this trend can explain the increasing searches in 40 out of the 45 countries. For countries like Hong Kong, Japan, Mexico, Qatar, and Turkey that scored low, the decrease in popularity rate for interest in the nursing profession the reason could be cultural and unsatisfactory working conditions or job satisfaction. ${ }^{27-30}$

\section{Future Considerations}

Career choices can vary depending on time variation and contingent on location or country as shown in this report. Notwithstanding, these are not the only determinants that can alter the choice of the health profession to pursue. The extent of government support or structure of the educational system may also alter this preference. In some countries, scholarships are available that may entice prospective students to undertake a career in these health professions or it may be scarce and competitive that it may be the only means for an individual to ascend from poverty. The creation of cadres is also common in developing countries to create a support workforce to assist doctors, dentists, and nurses. This can offset the decline of interest in health professions education or boost the interest.

\section{Limitations}

Despite exhaustively using available data from GT, there are other online sources of information like Facebook or Twitter that can consolidate or give another perspective to these findings. This study was also limited to the decades from 2010 to 2019 , and data available are based on the RSV of 45 countries out of 197. Moreover, the RSV is not the actual objective data that can be fully relied upon in determining the search interests for health professions education. Correlation can be drawn from qualitative studies done through focus group discussions. The search terms DD, MD, and ND are in no way representative of all the health professions. Prospective reports should cover other health professions like medical technology, physical therapy, optometry, and others.

\section{CONCLUSION}

This research study showed that the global search interests for $\mathrm{DD}$ and ND are low compared to MD. The searches for MD and ND significantly increased from 2010 to 2019 while DD decreased from 2010 to 2015 but somehow stabilized from 2016 to 2019. Although not significant, low rise in the interests of DD was seen in the countries of Australia, Canada, India, Pakistan, South Africa, and the USA. While there was an increase in the interest for MD in 31 countries and for ND in 40 countries, the decline in the interest for MD in 14 countries and ND in five countries should be alarming. The redundant appearance in the declining interests for MD and ND by the countries Hong Kong, Japan, Mexico, and Turkey should be of interest to the government or educational ministry of these countries. The forecasted trendline of the RSV of each search terms will surge intermittently across the year 2020 according to the 12-month forecast. These interest towards these health professions will rise within the third quarter but decline abruptly at the end of the year.

\section{References}

1. Sustainable development knowledge platform. United Nations, Department of Economic and Social Affairs https://sustainabledevelopment.un.org/sdgs. Accessed January 1, 2020.

2. McPake B, Maeda A, Araujo EC, Lemiere C, El Maghraby A, Cometto G. Why do health labour market forces matter? Bull World Health Organ. 2013;91(11):841-846.

3. Global Burden of Disease Study C. Global, regional, and national incidence, prevalence, and years lived with disability for 301 acute and chronic diseases and injuries in 188 countries, 1990-2013: a systematic analysis for the Global Burden of Disease Study 2013. Lancet. 2015;386(9995):743-800.

4. Bodenheimer T, Berenson RA, Rudolf P. The primary care-specialty income gap: why it matters. Ann Intern Med. 2007;146(4):301-306.

5. Gorman DF, Brooks PM. On solutions to the shortage of doctors in Australia and New Zealand. Med JAust. 2009;190(3):152-156.

6. Marten R, McIntyre D, Travassos C, et al. An assessment of progress towards universal health coverage in Brazil, Russia, India, China, and South Africa (BRICS). Lancet. 2014;384(9960):2164-2171.

7. Chen L, Evans T, Anand S, et al. Human resources for health: overcoming the crisis. Lancet. 2004;364(9449):1984- 1990.

8. Hagopian A, Thompson MJ, Fordyce M, Johnson KE, Hart LG. The migration of physicians from sub-Saharan Africa to the United States of America: measures of the African brain drain. Hum Resour Health. 2004;2(1):17.

9. Hernandez P, Dräger S, Evans D, Tan-Torres T, Dal Poz M. Measuring expenditure for the health workforce: challenges and evidence. 2006; http://www.who.int/hrh/documents/en/Accessed January 1, 2020. 
10. Speybroeck N, Ebener S, Sousa A, Paraje G, Evans D, Prasad A. Inequality in access to human resources for health: measurement issues. 2006; http://www.who.int/hrh/documents/en/.

11. Anand S, Barnighausen T. Human resources and health outcomes: cross-country econometric study. Lancet. 2004;364(9445):1603-1609.

12. Sousa A, Tandon A, Prasad A, Dal Poz M, Evans D. Measuring the efficiency of health workers in attaining health outcomes across sub national units in Brazil. 2006; $h$ ttp://www.who.int/hrh/documents/en/. Accessed January 1, 2020.

13. Prasad A, Tandon A, Sousa A, Ebener S, Evans D. Measuring the efficiency of human resources for health in attaining health outcomes across provinces in Viet Nam. 2006; http://www.who.int/hrh/documents/en/. Accessed January 1, 2020.

14. Lotto M, Ayala Aguirre PE, Rios D, Andrade Moreira Machado MA, Pereira Cruvinel AF, Cruvinel T. Analysis of the interests of Google users on toothache information. PLoS One. 2017;12(10):e0186059.

15. Rangarajan $P$, Mody SK, Marathe M. Forecasting dengue and influenza incidences using a sparse representation of Google trends, electronic health records, and time series data. PLoS Comput Biol. 2019;15(11):e1007518.

16. Quintanilha LF, Souza LN, Sanches D, Demarco RS, Fukutani KF. The impact of cancer campaigns in Brazil: a Google Trends analysis. Ecancermedicalscience. 2019;13:963.

17. Morsy S, Dang TN, Kamel MG, et al. Prediction of Zika-confirmed cases in Brazil and Colombia using Google Trends. pidemiol Infect. 2018;146(13):1625-1627.

18. Lee JY. Search trends preceding increases in suicide: A cross-correlation study of monthly Google search volume and suicide rate using transfer function models. J Affect Disord. 2020;262:155-164.

19. Nuti SV, Wayda B, Ranasinghe I, et al. The use of google trends in health care research: a systematic review. PLoS One. 2014;9(10):e109583.

20. Kothari S, Gray AR, Lyons K, Tan XW, Brunton PA. Vital bleaching and oral-health-related quality of life in adults: A systematic review and meta-analysis. J Dent. 2019;84:22-29.

21. Roy M, Moreau N, Rousseau C, Mercier A, Wilson A, Atlani-Duault L. Ebola and Localized Blame on Social Media: Analysis of Twitter and Facebook Conversations During the 2014-2015 Ebola Epidemic. Cult Med Psychiatry. 2019.

22. Masri S, Jia J, Li C, et al. Use of Twitter data to improve Zika virus surveillance in the United States during the 2016 epidemic. BMC Public Health. 2019;19(1):761.

23. Voinea-Griffin A, Solomon ES. Dentist shortage: an analysis of dentists, practices, and populations in the underserved areas. J Public Health Dent. 2016;76(4):314-319.

24. Dudko Y, Kruger E, Tennant M. Shortage of dentists in Outer Regional and Remote areas and long public dental waiting lists: Changes over the past decade. Aust J Rural Health. 2018.

25. Gazibara T, Kurtagic I, Maric G, et al. Perception of First-Year Versus Sixth-Year Medical Students in Serbia on Studying Medicine and Postgraduate Career. Acta Clin Croat. 2019;58(2):371-378.

26. Yoo BK, Kim M, Sasaki T, Ward D, Spetz J. The Impact of Economic Recession On Registered Nurse Workforce Supply in California. Nurs Econ. 2017;35(1):21-29.

27. Sawada A. The nurse shortage problem in Japan. Nurs Ethics. 1997;4(3):245-252.

28. Bond ML, Gray JR, Baxley S, Cason CL, Denke L, Moon M. Voices of Hispanic students in baccalaureate nursing programs: are we listening? Nurs Educ Perspect. 2008;29(3):136-142.

29. Gok AU, Kocaman G. Reasons for leaving nursing: a study among Turkish nurses. Contemp Nurse. 2011;39(1):65-74.

30. Chan ZC, Tam WS, Lung MK, Wong WY, Chau CW. On nurses moving from public to private hospitals in Hong Kong. J Clin Nurs. 2013;22(9-10):1382-1390. 